\title{
Serum Resistin as a Biological Marker for Coronary Artery Disease and Restenosis in Type 2 Diabetic Patients
}

\author{
Young Keun On, MD, PhD; Hyeong Kyu Park, MD, PhD*; \\ Min Su Hyon, MD, PhD*; Eun-Seok Jeon, MD, PhD
}

\begin{abstract}
Background Resistin is an adipocyte-secreted hormone. The relationship between circulating resistin concentrations and atherosclerotic coronary artery disease (CAD) in type 2 diabetic patients, if any, remains poorly understood. Serum resistin concentrations were investigated in type 2 diabetic patients with CAD (DMCAD), and compared with the concentrations in diabetics patients without CAD (diabetes mellitus, DM). Whether resistin levels are associated with increased restenosis rates in diabetic patients with CAD after successful coronary stenting was also investigated.

Methods and Results Fasting serum resistin, adiponectin, and leptin concentrations were measured in 45 DMCAD patients and $47 \mathrm{DM}$ controls. The percutaneous coronary intervention study included $70 \mathrm{DMCAD}$ patients, who underwent elective and successful coronary bare metal stent (BMS) implantation for the treatment of de novo lesions. Serum resistin concentrations were higher in the DMCAD patients than in the DM controls $(5.75 \pm 3.21$ vs $2.53 \pm 2.47 \mathrm{ng} / \mathrm{ml}$, mean \pm SEM, $\mathrm{p}<0.001)$, and these differences were persistent regardless of age or body mass index. Insulin resistance indices, as assessed via homeostasis model assessment (HOMA-IR) correlated significantly with resistin concentrations $(\mathrm{r}=0.4, \mathrm{p}<0.001)$. Resistin was an independent factor, and was associated with DMCAD in the multivariate analysis. In the percutaneous coronary intervention study, HOMAIR was not associated with subsequent restenosis rates after BMS implantation in DMCAD patients. Pre-procedural serum resistin concentrations were higher in restenosis group than in the patients without restenosis.

Conclusions Serum resistin may prove to be a useful biological marker for CAD and restenosis in patients with type 2 DM. (Circ J 2007; 71: 868-873)
\end{abstract}

Key Words: Adipocytokine; Coronary artery disease; Resistin; Restenosis; Type 2 diabetes mellitus

$\mathbf{T}$ he risk of developing atherosclerotic cardiovascular disease is known to be 2-4-fold higher in patients with type 2 diabetes mellitus (DM) than in nondiabetic subjects. Clustering of insulin resistance (IR), metabolic dyslipidemia, and chronic inflammation may account for some of these proatherosclerotic effects.

Adipose tissue is known to secrete several hormones and cytokines that are actively involved in energy, glucose, and lipid homeostasis. Adipocytokines, such as tumor necrosis factor a (TNFa), leptin, and adiponectin, may modulate both intermediate metabolism and energy balance! Recently, a new adipocytokine, resistin, has been suggested as the link between obesity and IR? Serum concentrations of resistin are elevated in human subjects who are obese, as well as in those with type 2 DM4 Resistin is expressed by both human monocytes and adipocytes, and in vitro the mRNA level is upregulated during differentiation of monocytes into macrophages5 However, the physiological role of resistin in the development of atherosclerosis remains

(Received September 11, 2006; revised manuscript received January 24, 2007; accepted March 2, 2007)

Division of Cardiology, Department of Medicine, Samsung Medical Center, Sungkyunkwan University School of Medicine, *Department of Internal Medicine, Soonchunhyang University Hospital, Seoul, South Korea

Mailing address: Eun-Seok Jeon, MD, PhD, Division of Cardiology, Department of Medicine, Cardiac and Vascular Center, Samsung Medical Center, Sungkyunkwan University School of Medicine, 50 Irwon-dong, Kangnam-gu, 135-710, Seoul, South Korea. E-mail: eunseokjeon@samsung.com unknown.

In order to characterize the relationship between resistin and atherosclerosis, we measured the serum concentrations of resistin in patients with type $2 \mathrm{DM}$ and atherosclerotic coronary artery disease (DMCAD). We also analyzed the relationship between resistin concentration and restenosis rates in DMCAD patients who had successful implantation of a bare metal stent (BMS).

\section{Methods}

Study 1: Biological Marker for DM Patients With CAD

Study Patients Forty-five consecutive patients with type $2 \mathrm{DM}$ who had significant stenosis in at least 1 major coronary artery, or who had a history of myocardial infarction, or who had previously undergone percutaneous coronary intervention (PCI) or coronary artery bypass grafts, were included in the DMCAD group; 47 consecutive patients with type $2 \mathrm{DM}$ without the evidence of $\mathrm{CAD}$ were the controls. None of them had any history of angina or other heart diseases, and had abnormal resting ECG findings or positive results for an exercise stress test. The exclusion criteria were as follows: evidence of current infective, inflammatory, or neoplastic conditions; hepatic or renal dysfunction; currently taking thiazolidinedione or insulin; and participation in a drug or device trial within the previous 30 days.

Informed consent for this study was given by all patients. The protocols of this study were consistent with the ethical guidelines of the 1975 Helsinki Declaration, and the 
Table 1 Clinical and Metabolic Characteristics of the Patients With Type 2 DM With and Without Atherosclerotic CAD

\begin{tabular}{|c|c|c|c|}
\hline & $D M C A D(n=45)$ & DM control $(n=47)$ & p value \\
\hline Gender (M:F) & $27: 18$ & $30: 17$ & $N S$ \\
\hline Age (years) & $64 \pm 2$ & $56 \pm 1$ & $<0.05$ \\
\hline Weight $(\mathrm{kg})$ & $66 \pm 2$ & $66 \pm 1$ & $N S$ \\
\hline$B M I\left(\mathrm{~kg} / \mathrm{m}^{2}\right)$ & $25.2 \pm 0.5$ & $24.6 \pm 0.4$ & NS \\
\hline Waist circumference $(\mathrm{cm})$ & $92 \pm 2$ & $87 \pm 1$ & $<0.05$ \\
\hline Hip circumference $(\mathrm{cm})$ & $100 \pm 2$ & $96 \pm 1$ & $<0.05$ \\
\hline Waist-hip ratio & $0.92 \pm 0.01$ & $0.91 \pm 0.01$ & NS \\
\hline Smoking & $13(29 \%)$ & $13(28 \%)$ & NS \\
\hline$S B P(m m H g)$ & $128 \pm 6$ & $131 \pm 7$ & NS \\
\hline$D B P(m m H g)$ & $82 \pm 3$ & $82 \pm 3$ & NS \\
\hline Sulfonvlurea (\%) & 96 & 83 & NS \\
\hline Metformin (\%) & 26 & 30 & NS \\
\hline Fasting glucose $(\mathrm{mmol} / \mathrm{L})$ & $8.63 \pm 0.61$ & $9.11 \pm 0.48$ & NS \\
\hline Fasting insulin $(\mathrm{pmol} / \mathrm{L})$ & $90.1 \pm 11.0$ & $63.5 \pm 7.0$ & $<0.05$ \\
\hline$H O M A-I R$ & $5.65 \pm 0.80$ & $4.19 \pm 0.58$ & NS \\
\hline Hemoglobin Alc (\%) & $8.2 \pm 0.3$ & $8.0 \pm 0.3$ & NS \\
\hline$T C(m g / d l)$ & $195 \pm 9$ & $200 \pm 7$ & NS \\
\hline$T G(m g / d l)$ & $217 \pm 22$ & $239 \pm 34$ & NS \\
\hline$H D L-C(m g / d l)$ & $42 \pm 3$ & $46 \pm 2$ & NS \\
\hline$L D L-C(m g / d l)$ & $107 \pm 6$ & $106 \pm 6$ & NS \\
\hline$C R P(\mathrm{mg} / \mathrm{dl})$ & $0.41 \pm 0.24$ & $0.22 \pm 0.03$ & NS \\
\hline Uric acid $(\mathrm{mg} / \mathrm{dl})$ & $5.51 \pm 0.57$ & $5.22 \pm 0.58$ & NS \\
\hline Leptin $(\mathrm{ng} / \mathrm{ml})$ & $11.39 \pm 2.23$ & $6.45 \pm 0.83$ & $<0.05$ \\
\hline Adiponectin $(\mu \mathrm{g} / \mathrm{ml})$ & $6.63 \pm 0.98$ & $4.44 \pm 0.41$ & $<0.05$ \\
\hline Resistin $(\mathrm{ng} / \mathrm{ml})$ & $5.75 \pm 0.58$ & $2.53 \pm 0.37$ & $<0.001$ \\
\hline
\end{tabular}

Values are mean $\pm S E M$.

$D M$, diabetes mellitus; $C A D$, coronary artery disease; BMI; body mass index [weight $(\mathrm{kg}) / h$ height $\left.\left(\mathrm{m}^{2}\right)\right]$; SBP, systolic blood pressure; $D B P$, diastolic blood pressure; HOMA-IR, homeostasis model of assessment for insulin resistance; TC, total cholesterol; TG, triglyceride; HDL-C, high-density lipoprotein-cholesterol; $L D L$-C, low-density lipoprotein-cholesterol; CRP, C-reactive protein.

institutional review boards ensured appropriate ethical and bioethical conduct.

We measured fasting serum concentrations of resistin, adiponectin, leptin, and lipids in all study patients. IR was quantified using the homeostasis model of assessment (HOMA-IR).

Blood Sampling and Analysis Peripheral venous blood samples were obtained from all patients after fasting. The serum samples were processed immediately, coded, and then stored at $-70^{\circ} \mathrm{C}$ until blind analysis was conducted at the end of the study. Serum resistin concentrations were measured by enzyme-linked immunosorbent assay (ELISA) method using a commercial kit (LINCO Research Inc, MO, USA). Serum concentrations of normal healthy people were $1.92 \pm 0.37 \mathrm{ng} / \mathrm{ml}$ (mean \pm SEM, range $0.29-3.74 \mathrm{ng} / \mathrm{ml}$ ). Serum concentrations of leptin and adiponectin were measured by radioimmunoassay (RIA) using commercial kits (LINCO Research Inc). Serum insulin concentrations were measured by RIA (Biosource Inc, Belgium).

\section{Study 2: Biological Marker for Restenosis After BMS Implantation in DM Patients}

Study Patients This study was designed as prospective cohort study. The PCI study included $70 \mathrm{DM}$ patients who suffered from symptomatic CAD and had undergone elective and successful BMS implantation for the treatment of de novo lesions. The PCI procedure was performed using a femoral or radial approach according to standard techniques. PCI was defined as successful when the residual luminal stenosis of the dilated segment was visually estimated to be $<20 \%$ and when no major complications occurred, such as myocardial infarction, emergency bypass surgery during hospitalization, or death in hospital. During the PCI procedure, intravenous heparin was given as a bolus of 5,000 U.
Coronary stenosis was assessed in $\geq 2$ projections before and after PCI. The coronary BMS were Express (Boston Scientific, USA) or S7 (Medtronic Inc, USA).

This study included 35 DM patients who had developed restenosis after the implantation of BMS and 35 DM patients who had not. The exclusion criteria included any evidence of current infective, inflammatory, or neoplastic conditions; hepatic or renal dysfunction; and any participation in drug or device trials within the previous 30 days. All of the stented patients received aspirin (75-150 mg daily), or clopidogrel (300 mg prior to stenting, then $75 \mathrm{mg}$ daily for 1 month subsequent to stenting). Heparin was administered intra-arterially, and its dosage was titrated in order to ensure an activated clotting time of greater than $300 \mathrm{~s}$ during the procedure. There was no difference between the restenotic and non-restenotic groups in the type of BMS.

Blood Sampling and Analysis Peripheral venous blood samples were obtained from all patients prior to the procedure, and 6 months later. Serum samples were immediately processed, coded, and then stored at $-70^{\circ} \mathrm{C}$ until the end of the study, at which time they were subjected to a blind analysis. The serum interleukin (IL)- $\mathbb{\beta}$ and resistin concentrations were measured using the ELISA method (R\&D Systems and LINCO Research Inc, respectively). Serum concentrations of insulin were measured using RIA (LINCO Research Inc).

Angiographic Studies Angiography was conducted in at least 2 orthogonal views, and intracoronary nitroglycerin was administered prior to the key angiographic acquisitions during the stent procedure, and at the 6-month angiographic follow-up. Quantitative coronary angiographic (QCA) computer-assisted analysis (QUANTCOR-QCA, Siemens) was conducted on the end-diastolic frames acquired just prior to the wiring of the target lesion, after stenting and 


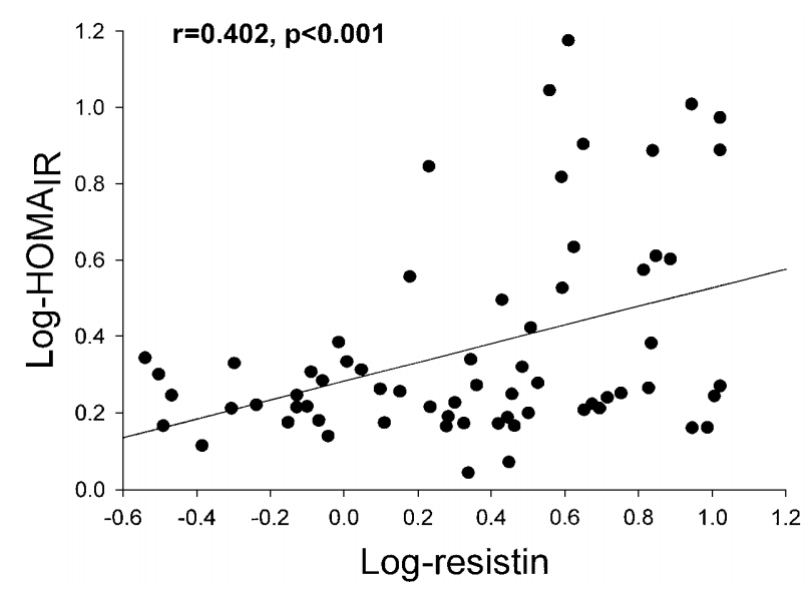

Fig 1. Simple correlation of serum resistin concentrations with the homeostasis model of assessment for insulin resistance (HOMA-IR).

upon follow-up, using the automated edge-detection system. Identical target lesion projections were used in all of the angiographic assessments. Restenosis was defined as a $\geq 50 \%$ diameter stenosis at the site of the treated lesion on the follow-up QCA.

\section{Statistical Analysis}

Statistical analyses were conducted using SPSS V10.0 (SPSS Inc, Chicago, IL, USA). Continuous variables are expressed as means \pm SEM, and were compared via unpaired, 2 -sided t-test analyses. The discrete variables were compared viax ${ }^{2}$ or Fisher's exact tests, as appropriate. Logistic regression analyses were also conducted, in order to assess the effects of risk factors on the development of CAD. The clinical and metabolic factors that were assigned a p-value $<1.0$ in the t-test analysis were selected, and analyzed via
Table 2 Multivariate Logistic Regression Analysis for CAD in Patients With Type 2 DM

\begin{tabular}{lcc}
\hline \hline Independent variable & Coefficient $\beta$ ) & p value \\
\hline Age & 3.902 & $N S$ \\
Smoking & 0.188 & $N S$ \\
Leptin & 0.331 & $N S$ \\
Adiponectin & 4.637 & $N S$ \\
Resistin & 23.379 & 0.020 \\
HOMA-IR & 9.040 & $N S$ \\
LDL-C & 3.030 & $N S$ \\
\hline
\end{tabular}

See Table 1 for abbreviations.

logistic regression. A p-value $<0.05$ was considered to be statistically significant.

\section{Results}

Resistin as a Biological Marker for DM Patients With CAD

The anthropometrics and metabolic characteristics of the type $2 \mathrm{DM}$ controls and DMCAD patients are shown in Table 1. Fasting serum insulin concentrations were higher in the DMCAD group, but fasting glucose, HOMA-IR, and lipid concentrations were not different. Serum leptin concentrations were higher in the DMCAD than in the control group $(11.39 \pm 2.23$ vs $6.45 \pm 0.83 \mathrm{ng} / \mathrm{ml}$, DMCAD vs control, $\mathrm{p}<0.05$, Table 1). Serum adiponectin concentrations were also higher in the DMCAD group than in the controls $(6.63 \pm$ 0.98 vs $4.44 \pm 0.41 \mu \mathrm{g} / \mathrm{ml}$, DMCAD vs control, $\mathrm{p}<0.05)$. Serum resistin concentrations were also higher in the DMCAD group than in the controls $(5.75 \pm 0.58$ vs $2.53 \pm$ $0.37 \mathrm{ng} / \mathrm{ml}$, DMCAD vs control, $\mathrm{p}<0.001)$. The HOMA-IR concentrations did not differ between the 2 groups. Serum resistin concentrations had no correlations with weight, body mass index (BMI), waist circumference, blood pressure, or serum concentrations of lipids, fasting glucose, insulin,

Table 3 Clinical, Pharmacological and Metabolic Characteristics of Type 2 Diabetic Patients With and Without Restenosis After Coronary Bare Metal Stent Implantation

\begin{tabular}{|c|c|c|c|}
\hline & $\begin{array}{c}\text { Non-restenosis } \\
(n=35)\end{array}$ & $\begin{array}{c}\text { Restenosis } \\
(n=35)\end{array}$ & $p$ value \\
\hline Gender $(M: F)$ & $17: 18$ & $20: 15$ & $N S$ \\
\hline Age (years) & $62 \pm 1.8$ & $64 \pm 1.4$ & NS \\
\hline$B M I\left(\mathrm{~kg} / \mathrm{m}^{2}\right)$ & $25.4 \pm 0.9$ & $25.1 \pm 0.6$ & $N S$ \\
\hline Hypertension (\%) & 74 & 77 & $N S$ \\
\hline Smoking (\%) & 29 & 31 & $N S$ \\
\hline$T C(m g / d l)$ & $182 \pm 10$ & $191 \pm 10$ & $N S$ \\
\hline$T G(m g / d l)$ & $216 \pm 29$ & $225 \pm 22$ & $N S$ \\
\hline$L D L-C(m g / d l)$ & $110 \pm 11$ & $104 \pm 7$ & $N S$ \\
\hline$C R P(\mathrm{mg} / \mathrm{dl})$ & $1.29 \pm 0.66$ & $1.09 \pm 0.42$ & $N S$ \\
\hline ACE inhibitor (\%) & 39 & 45 & $N S$ \\
\hline$A R B(\%)$ & 10 & 10 & $N S$ \\
\hline$\beta$-blocker (\%) & 74 & 61 & NS \\
\hline Ca-channel blocker (\%) & 26 & 23 & $N S$ \\
\hline Statin $(\%)$ & 26 & 26 & $N S$ \\
\hline Sulfonylurea (\%) & 52 & 55 & $N S$ \\
\hline Insulin $(\%)$ & 26 & 23 & $N S$ \\
\hline Hemoglobin Alc (\%) & $7.95 \pm 0.48$ & $7.55 \pm 0.33$ & $N S$ \\
\hline$H O M A-I R$ & $7.55 \pm 3.09$ & $5.25 \pm 1.00$ & NS \\
\hline Resistin $(n g / m l)$ & $2.54 \pm 0.61$ & $4.09 \pm 0.42$ & $<0.05$ \\
\hline$F / U$ resistin $(n g / m l)$ & $2.98 \pm 0.64$ & $2.72 \pm 0.36$ & $N S$ \\
\hline$I L-\beta(p g / m l)$ & $4.40 \pm 3.71$ & $3.48 \pm 2.21$ & NS \\
\hline$F / U I L-\beta(p g / m l)$ & $5.42 \pm 4.90$ & $3.38 \pm 2.20$ & $N S$ \\
\hline
\end{tabular}

Values are mean $\pm S E M$.

$A C E$, angiotensin-converting enzyme; $A R B$, angiotensin 2 receptor blocker; $F / U$, follow up; IL- $\beta$, interleukin- $\beta$. See Table 1 for other abbrebiations. 
Table 4 QCA of Type 2 Diabetic Patients With and Without Restenosis After Coronary Bare Metal Stent Implantation

\begin{tabular}{lccc}
\hline \hline & $\begin{array}{c}\text { Non-restenosis } \\
(n=35)\end{array}$ & $\begin{array}{c}\text { Restenosis } \\
(n=35)\end{array}$ & $p$ value \\
\hline LAD/LCX/RCA & $19 / 5 / 11$ & $18 / 6 / 11$ & $N S$ \\
RD $(\mathrm{mm})$ & $2.94 \pm 0.11$ & $2.88 \pm 0.12$ & $N S$ \\
Before MLD $(\mathrm{mm})$ & $0.54 \pm 0.06$ & $0.54 \pm 0.06$ & $N S$ \\
Stent diameter $(\mathrm{mm})$ & $2.85 \pm 0.09$ & $2.92 \pm 0.08$ & $N S$ \\
Stent length $(\mathrm{mm})$ & $15.8 \pm 0.90$ & $14.9 \pm 0.88$ & $N S$ \\
Final MLD $(\mathrm{mm})$ & $2.75 \pm 0.09$ & $2.74 \pm 0.12$ & $N S$ \\
Acute gain $(\mathrm{mm})$ & $2.21 \pm 0.07$ & $2.20 \pm 0.10$ & $N S$ \\
Residual $D S(\%)$ & $10.6 \pm 1.2$ & $10.8 \pm 2.2$ & $N S$ \\
F/U MLD $(\mathrm{mm})$ & $2.16 \pm 0.07$ & $1.01 \pm 0.09$ & $<0.001$ \\
Late loss $(\mathrm{mm})$ & $0.05 \pm 0.13$ & $1.19 \pm 0.14$ & $<0.001$ \\
Loss index & $0.02 \pm 0.06$ & $0.54 \pm 0.04$ & $<0.001$ \\
\hline
\end{tabular}

Values are mean $\pm S E M$.

QCA, quantitative computer-assisted angiographic analysis; LAD, left anterior descending; LCX, left circumflex; RCA, right coronary artery; $R D$, reference diameter; $M L D$, minimal lumen diameter; $D S$, diameter stenosis. See Table 3 for other abbrebiation.

\section{HOMA-IR}

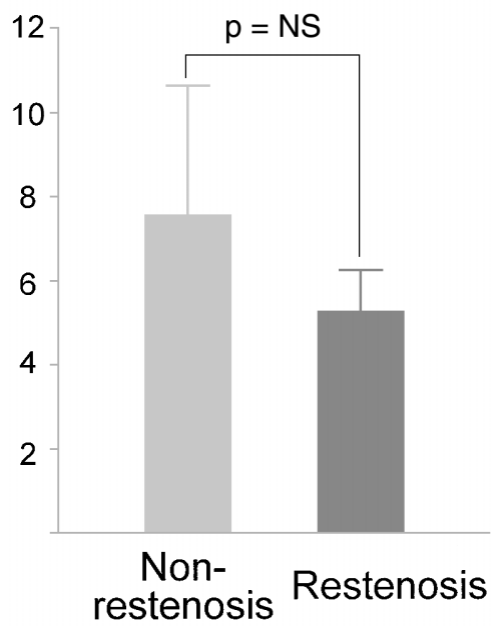

\section{Resistin}

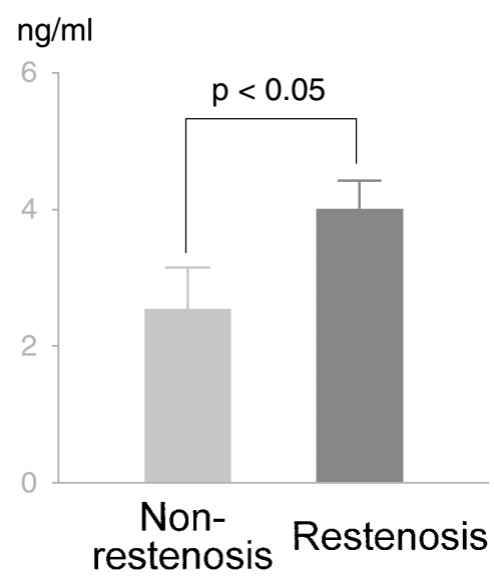

Fig 2. Homeostasis model of assessment for insulin resistance (HOMA-IR) levels in the restenotic and non-restenotic groups of patients with type 2 diabetes mellitus. Serum resistin levels were higher in the restenotic group than in those with nonrestenosis. adiponectin, or leptin. The HOMA-IR significantly correlated with serum resistin concentration $(\mathrm{r}=0.4, \mathrm{p}<0.001$, Fig 1).

The serum resistin concentrations did not differ significantly according to the results of coronary angiography $(5.59 \pm 0.98$ vs $5.95 \pm 0.85$ vs $5.53 \pm 0.88 \mathrm{ng} / \mathrm{ml}, 1$-vessel vs 2-vessel vs 3-vessel disease, $\mathrm{p}=\mathrm{NS}$ ).

In the multivariate analysis, of age, smoking, low-density lipoprotein-cholesterol, the serum concentrations of resistin, leptin and adiponectin, and HOMA-IR, only resistin concentration was significantly related to DMCAD (Table 2).

\section{Resistin as a Biological Marker for Restenosis in BMS Implantation in DM Patients}

The PCI study included 35 patients with type 2 DM who developed restenosis after BMS implantation for de novo lesions and $35 \mathrm{DM}$ patients who did not experience restenosis. There were no statistical differences in the clinical, pharmacological, and procedural characteristics of the 2 groups (Tables 3,4). According to the QCA analysis, there were no statistical differences in the reference diameter, minimum lumen diameter, percent diameter stenosis, or acute gain before and after implantation of the BMS.

Only the pre-procedural serum resistin concentrations were significantly higher in the restenosis group (4.09 \pm 0.42 vs $2.54 \pm 0.61 \mathrm{ng} / \mathrm{ml}$, restenotic vs non-restenotic group, $\mathrm{p}<0.05$, Table 3 , Fig 2). However, the correlation between the serum resistin concentration and late loss or late loss index by QCA was not significant (log-resistin and late loss, $\mathrm{r}=0.232, \mathrm{p}=0.092$; log-resistin and late loss index, $\mathrm{r}=0.116$, $\mathrm{p}=0.263$ ).

Post-procedural serum resistin concentrations at 6 months were not significantly different between groups $(2.72 \pm 0.36$ vs $2.98 \pm 0.64 \mathrm{ng} / \mathrm{ml}$, restenosis vs non-restenosis group, $\mathrm{p}=\mathrm{NS}$ ).

Serum IL-1 13 concentrations and HOMA-IR were not different between groups.

\section{Discussion}

Metabolic syndrome is associated with increased risk of cardiovascular disease and it is considered that there is association between adipocytokine, long-term weight fluctuation and metabolic syndrome6

Adipose tissue secretes several hormones and cytokines that are actively involved in energy, glucose, and lipid homeostasis. Adipocytokines, such as TNFa, leptin, and adiponectin, appear to modulate both intermediate metabolism and energy balance, and may link IR to cardiovascular disease.

Leptin, an adipocyte-derived hormone that is known to 
have effects on both food intake and energy expenditure, may constitute the link between obesity, diabetes, cardiovascular risk, and ventricular hypertrophy? In a prospective study, higher concentrations of leptin in hypercholesterolemia were associated with increased risk of future coronary events8

Adiponectin, which is expressed by differentiated adipocytes, exhibits a host of biofunctions, including antidiabetic, antiatherosclerotic, and antiinflammatory effects?-11

Recently, a novel adipocytokine, resistin, was identified in mice during screening of genes associated with adipocyte differentiation; ${ }^{2}$ however, its expression was downregulated in mature adipocytes that were exposed to rosiglitazone, an insulin-sensitizing drug that is used routinely in the treatment of type 2 DM. In mice, the retn gene was expressed exclusively in the white adipose tissue. Resistin protein is also detectable in both adipocytes and blood. Administration of resistin to wild-type mice worsens glucose homeostasis and insulin sensitivity. Furthermore, antibody-mediated neutralization of resistin, by the injection of antibodies into mice with diet-induced obesity, reduces blood glucose concentrations and concomitantly enhances insulin sensitivity. Therefore, resistin has been suggested to be a link between obesity and IR!'2,13 However, its relevance to human DM remains unclear at this point. In humans, the association of serum resistin with IR is still controversial. Silha et a ${ }^{14}$ reported that resistin concentrations were not correlated with BMI, although the concentrations were correlated significantly with HOMA-IR. In Pima Indians, high serum resistin concentrations were associated with increases in adiposity, but not with any exacerbation of IR 15 In a study of patients with type $2 \mathrm{DM}$, serum human resistin concentrations were not correlated significantly with either BMI or HOMA-IR! 6

In a study of lung inflammation, the proteins induced during inflammation were referred to as the "found in inflammatory zone" (FIZZ1) proteins 17 Resistin was identified as FIZZ3 and was involved with inflammation. TNFa has been shown to be elevated in IR and to also antagonize the action of insulin!2,18 Serum resistin concentrations have been correlated with the concentrations of C-reactive protein.$^{19}$ However, IL-6 is not a major determinant in the regulation of the expression of resistin ${ }^{20}$ In an in vitro study, endothelial cells, which had been incubated with resistin, enhanced/stimulated endothelin-1 release, and also upregulated the expression of vascular cell adhesion molecule-1 and monocyte chemoattractant chemokine-121 These findings suggest that resistin may be associated with cardiovascular disease in metabolic syndrome.

Serum concentrations of resistin are elevated in humans who are obese, 3 as well as in patients with type 2 DM. Resistin is expressed by both human monocytes and adipocytes, and the differentiation of monocytes into macrophages in vitro is also associated with a concomitant increase in the level of resistin mRNA5. Ozawa et al demonstrated that serum resistin concentrations correlated strongly with promoter polymorphisms, as well as type $2 \mathrm{DM}$ and metaanalysis, which supports the notion of a relationship between resistin gene polymorphisms and type $2 \mathrm{DM}^{22}$ Calabro et al indicated that resistin promoted the proliferation of smooth muscle cells via the activation of extracellular signal-regulated kinase $1 / 2$ and phosphatidylinositol 3-kinase in vitro, and also suggested that resistin might have some effect on restenosis ${ }^{23}$ Hyperuricemia is also considered to be associated with IR ${ }_{2}^{24}$ but we could not find a correlation of serum uric acid concentration with HOMAIR.

\section{Study Limitations}

A relatively small number of subjects were enrolled in this study, and our power to detect associations between resistin and the selected clinical parameters might have been attenuated. Therefore, a larger randomized controlled study is required to give the definitive answer.

\section{Conclusions}

As compared with type $2 \mathrm{DM}$ patients who did not have $\mathrm{CAD}$, the serum resistin concentrations were elevated in DMCAD patients, and the pre-procedural serum resistin concentrations were higher in type 2 DM patients with restenosis after stenting with a BMS than in those who did not experience restenosis. Serum resistin might be a biological marker for CAD and restenosis in type $2 \mathrm{DM}$ patients. Further studies are required in order to clarify resistin's role in the development of atherosclerosis in patients with type $2 \mathrm{DM}$.

\section{References}

1. Havel PJ. Control of energy homeostasis and insulin action by adipocyte hormones: Leptin, acylation stimulating protein, and adiponectin. Curr Opin Lipidol 2002; 13: $51-59$.

2. Steppan CM, Bailey ST, Bhat S, Brown EJ, Banerjee RR, Wright $\mathrm{CM}$, et al. The hormone resistin links obesity to diabetes. Nature 2001; 409: 307-312.

3. Degawa-Yamauchi M, Bovenkerk JE, Juliar BE, Watson W, Kerr K, Jones R, et al. Serum resistin (FIZZ3) protein is increased in obese humans. J Clin Endocrinol Metab 2003; 88: 5452-5455.

4. Youn BS, Yu KY, Park HJ, Lee NS, Min SS, Youn MY, et al. Plasma resistin concentrations measured by enzyme-linked immunosorbent assay using a newly developed monoclonal antibody are elevated in individuals with type 2 diabetes mellitus. J Clin Endocrinol Metab 2004; 89: 150-156.

5. Patel L, Buckels AC, Kinghorn IJ, Murdock PR, Holbrook JD, Plumpton $\mathrm{C}$, et al. Resistin is expressed in human macrophages and directly regulated by PPAR gamma activators. Biochem Biophys Res Commun 2003; 300: 472-476.

6. Zhang H, Tamakoshi K, Yatsuya H, Murata C, Wada K, Otsuka R, et al. Long-term body weight fluctuation is associated with metabolic syndrome independent of current body mass index among Japanese men. Circ J 2005; 69: 13-18.

7. Sader S, Nian M, Liu P. Leptin A novel link between obesity, diabetes, cardiovascular risk, and ventricular hypertrophy. Circulation 2003; 108: 644-646.

8. Wallace AM, McMahon AD, Packard CJ, Kelly A, Shepherd J, Gaw A, et al. Plasma leptin and the risk of cardiovascular disease in the West of Scotland Coronary Prevention Study (WOSCOPS). Circulation 2001; 104: 3052-3056.

9. Matsuzawa Y, Funahashi T, Kihara S, Shimomura I. Adiponectin and metabolic syndrome. Arterioscler Thromb Vasc Biol 2004; 24: 29-33.

10. Maahs DM, Ogden LG, Kinney GL, Wadwa P, Snell-Bergeon JK, Dabelea D, et al. Low plasma adiponectin levels predict progression of coronary artery calcification. Circulation 2005; 111: 747-753.

11. Pischon T, Girman CJ, Hotamisligil GS, Rifai N, Hu FB, Rimm EB. Plasma adiponectin levels and risk of myocardial infarction in men. JAMA 2004; 291: 1730-1737.

12. Shuldiner AR, Yang R, Gong DW. Resistin, obesity and insulin resistance: The emerging role of the adipocyte as an endocrine organ. N Engl J Med 2001; 345: 1345 - 1346.

13. Steppan CM, Lazar MA. The current biology of resistin. J Intern Med 2004; 255: 439-447.

14. Silha JV, Krsek M, Skrha JV, Sucharda P, Nyomba BL. Plasma resistin, adiponectin and leptin levels in lean and obese subjects: Correlations with insulin resistance. Eur J Endocrinol 2003; 149: 331 - 335.

15. Volarova de Courten B, Degawa-Yamauchi M, Considine RV, Tataranni PA. High serum resistin is associated with an increase in adiposity but not a worsening of insulin resistance in Pima Indians. Diabetes 2004; 53: 1279-1284. 
16. Pfutzner A, Langenfeld M, Kunt T, Lobig M, Forst T. Evaluation of human resistin assays with serum from patients with type 2 diabetes and different degrees of insulin resistance. Clin Lab 2003; 49: 571 576.

17. Holcomb IN, Kabakoff RC, Chan B, Baker TW, Gurney A, Henzel $\mathrm{W}$, et al. FIZZ1, a novel cysteine-rich secreted protein associated with pulmonary inflammation, defines a new gene family. EMBO J 2000; 19: 4046-4055.

18. Borst SE. The role of TNF-alpha in insulin resistance. Endocrine 2004; 23: $177-182$

19. McTernan PG, Fisher FM, Valsamakis G, Chetty R, Harte A, McTernan CL, et al. Resistin and type 2 diabetes: Regulation of resistin expression by insulin and rosiglitazone and the effects of recombinant resistin on lipid and glucose metabolism in human differentiated adipocytes. J Clin Endocinol Metab 2003; 88: 6098 6106.

20. Steppan CM, Lazar MA. Resistin and obesity-associated insulin resistance. Trends Endocrinol Metab 2002; 13: 18-23.

21. Verma S, Li SH, Wang CH, Fedak PWM, Li RK, Weisel RD, et al. Resistin promotes endothelial cell activation: Further evidence of adipokine-endothelial interaction. Circulation 2003; 108: 736-740.

22. Osawa H, Yamada K, Onuma H, Murakami A, Ochi M, Kawata H, et al. The G/G genotype of a resistin single-nucleotide3 polymorphism at -420 increases type 2 diabetes mellitus susceptibility by inducing promoter activity through specific binding of Sp1/3. Am J Hum Gen 2004; 75: 678-686.

23. Calabro P, Samudio I, Willerson JT, Yeh ETH. Resistin promotes smooth muscle cell proliferation through activation of extracellular signal-regulated kinase 1/2 and phosphatidylinositol 3-kinase pathways. Circulation 2004; 110: 3335-3340.

24. Yoo TW, Sung KC, Shin HS, Kim BJ, Kim BS, Kang JH, et al. Relationship between serum uric acid concentration and insulin resistance and metabolic syndrome. Circ J 2005; 69: 928-933. 